\title{
Solvothermal Synthesis of Cerium-Doped Titania Nanostructured Materials Modified with Acetylacetone for Solar-Driven Photocatalysis
}

\author{
Bruno A. T. Menezes, ${ }^{a}$ Daniel E. B. Moreira, ${ }^{a}$ Hugo A. Oliveira, ${ }^{b}$ Lippy F. Marques ${ }^{a}$ and \\ Juliana F. Lima ${ }^{\circledR *, a}$ \\ ${ }^{a}$ Grupo de Materiais Inorgânicos Multifuncionais (GMIM), Instituto de Química (IQ), Universidade \\ do Estado do Rio de Janeiro, 20550-900 Rio de Janeiro-RJ, Brazil \\ ${ }^{b}$ Departamento de Engenharia Química e de Petróleo (TEQ), Universidade Federal Fluminense, \\ 24210-240 Niterói-RJ, Brazil
}

\begin{abstract}
This study reports the preparation of nanostructured cerium-doped titanium dioxide photocatalysts containing different cerium concentrations by a modified sol-gel route involving the use of acetylacetone. The nanocrystalline powders had their structural, morphological, and optical properties characterized by X-ray diffraction, vibrational and Raman spectroscopy, thermogravimetric analysis, X-ray photoelectron spectroscopy, Brunauer, Emmett and Teller (BET) surface area analysis, scanning electron microscopy combined with energy dispersive X-ray spectroscopy, total reflection X-ray fluorescence, and diffuse reflectance spectroscopy. Cerium incorporation reduced the bandgap energy of the solids to values that allowed them to absorb visible light. Cerium presence improved the textural properties that are crucial for the catalytic process. The photocatalytic activities were evaluated through photodegradation experiments of methyl orange dye solution. The synthesis with acetylacetone as stabilizer provided nanostructured materials with higher $\mathrm{Ce}^{3+} / \mathrm{Ce}^{4+}$ ratio, which enhanced the photocatalytic activity. Smaller quantities of the doped photocatalysts afforded higher degradation rates than the rates reported in the literature.
\end{abstract}

Keywords: nanomaterials, titania, cerium, photocatalysis, solar radiation

\section{Introduction}

The environmental effects of industrial waste have increased considerably in the last decades, and great attention has been devoted to water decontamination. ${ }^{1,2}$ Organic dyes are commonly and widely employed in the textile industry, ${ }^{3}$ but they pollute water resources. The organic dyes that are used in the textile industry have high solubility in water, low degradation rates, and elevated toxicity, which makes them extremely hazardous. ${ }^{4,5}$ Effective industrial effluent treatment remains an environmental challenge. ${ }^{1,6}$ Concerning degradation processes, dyes are usually resistant to conventional methods and to UV-Vis light, and they are only partially biodegradable. In aquatic environments, the presence of dyes makes photosynthesis difficult. ${ }^{7}$ Therefore, highly efficient and economically viable treatments are necessary to guarantee low or no pollutant concentration in industrial effluents.

\footnotetext{
*e-mail: juliana.lima@uerj.br
}

Advanced oxidation processes (AOPs) are well known and have been extensively described in the literature. AOPs are commonly employed as fast and efficient methods to oxidize and to degrade different types of pollutants. ${ }^{8,9}$ These processes comprise mostly the formation of hydroxyl radicals $(\bullet \mathrm{OH})$, a class of reactive species. ${ }^{9,10}$ AOPs include chemical, photochemical, and hybrid or combined methods, which can occur in homogeneous or heterogeneous phases. These methods encompass the Fenton process, photocatalysis by semiconductors, ozonolysis, electrochemical oxidation, and sonolysis, among others. ${ }^{11}$ Photochemical AOPs are very interesting because they can be driven by natural, renewable solar radiation. ${ }^{12}$ Among the photochemical AOP methods, photo-Fenton and photocatalysis using semiconductors like $\mathrm{TiO}_{2}$ are the most popular. ${ }^{9}$ Table 1 lists some important information about photochemical methods.

Semiconductors can be photostimulated to degrade various non-biodegradable pollutants, and mild conditions can be applied. An adequate photocatalyst must be stable, inert, and amenable to modification in size, 
Table 1. Overview of photochemical advanced oxidative processes

\begin{tabular}{|c|c|c|}
\hline AOP & Condition & Observation \\
\hline Photocatalysis & $\begin{array}{l}\text { semiconductor / light, } \\
\text { semiconductors: } \mathrm{TiO}_{2} \text {, } \\
\mathrm{CeO}_{2}, \mathrm{ZnO}, \mathrm{Nb}_{2} \mathrm{O}_{5} \text {, etc. }\end{array}$ & $\begin{array}{l}\text { heterogeneous nature, } \\
\text { recyclable } \\
\text { photocatalyst, } \\
\text { wide } \mathrm{pH} \text { range, } \\
\text { possibility to apply } \\
\text { solar energy as light } \\
\text { source }\end{array}$ \\
\hline Photo-Fenton & $\mathrm{Fe}^{3+} / \mathrm{H}_{2} \mathrm{O}_{2} / \mathrm{UV}$ & $\begin{array}{l}\text { less energy intensive, } \\
\text { acidic } \mathrm{pH}(3-5) \\
\text { conditions, } \\
\text { residual sludge, } \\
\text { significant } \mathrm{pH} \text { influence }\end{array}$ \\
\hline Photo-ozonolysis & $\begin{array}{c}\mathrm{O}_{3} / \mathrm{UV} \\
\mathrm{O}_{3} / \mathrm{H}_{2} \mathrm{O}_{2} / \mathrm{UV}\end{array}$ & $\begin{array}{c}\text { Individual and direct } \\
\text { oxidation method, } \\
\text { pre-treatments, }{ }^{13} \\
\text { pH, ozone dose, and } \\
\text { temperature affect the } \\
\text { process } \\
\end{array}$ \\
\hline $\begin{array}{l}\text { Photo-electrochemical } \\
\text { oxidation }\end{array}$ & $\begin{array}{c}\mathrm{e}^{-} / \mathrm{TiO}_{2} / \mathrm{UV} \\
\mathrm{e}^{-} / \mathrm{Fe}^{3+} / \mathrm{H}_{2} \mathrm{O}_{2} / \mathrm{UV}\end{array}$ & $\begin{array}{c}\text { reactive species } \\
\text { generated by electricity, } \\
\text { unnecessity chemicals, } \\
\text { no secondary waste, } \\
\text { electrode surface } \\
\text { controls efficiency }\end{array}$ \\
\hline Photo-sonolysis & $\mathrm{O}_{3} / \mathrm{UV} / \mathrm{US}^{\mathrm{a}}$ & $\begin{array}{l}\text { ultrasound power and } \\
\text { frequency affect the } \\
\text { process }\end{array}$ \\
\hline
\end{tabular}

aUS: ultrasound; AOP: advanced oxidation processes.

morphology, and textural and optical properties for improved photocatalysis. ${ }^{10}$ Several metal oxides have been successfully employed as heterogeneous photocatalysts to degrade countless pollutants. ${ }^{14,15}$ However, most of these semiconductor photocatalysts show bandgap energy larger than $3.1 \mathrm{eV}(\lambda=300 \mathrm{~nm})$ and therefore require activation with UV radiation, which is not ideal for operative and daily applications. ${ }^{16,17}$ Furthermore, charge $\left(\mathrm{e}^{-} / \mathrm{h}^{+}\right)$recombination on heterogeneous photocatalyst surfaces may inactivate the photocatalysts, diminishing the decontamination process. ${ }^{14,18}$

$\mathrm{TiO}_{2}$ has been widely used as a semiconductor in photocatalysis for dye degradation, and many valuable works have been reported. ${ }^{15,19,20}$ Titania anatase, rutile, and brookite polymorphs have been well described, and the efficacy of crystalline anatase for photocatalysis has been demonstrated. ${ }^{21}$ On the other hand, highly nonstoichiometric nanocrystalline ceria nanoparticles display an ideal bandgap energy, which favors their participation in numerous redox processes. ${ }^{22-24}$ The synergism between titanium and cerium has promising application in the remediation of wastewater contaminated with dyes. ${ }^{25,26}$

Herein, we have synthesized nanostructured $\mathrm{TiO}_{2}$ doped with cerium ions by a modified sol-gel method and investigated how acetylacetone (acac), as stabilizer for solid lattices, preserved the $\mathrm{Ce}^{3+}$ state. ${ }^{15}$ The $\mathrm{Ce}^{3+}$-doped $\mathrm{TiO}_{2}$ absorbed visible light probably due to the defects produced by cerium introduction into the $\mathrm{TiO}_{2}$ crystal. We have extensively characterized the structural, morphological, and optical properties of the nanocrystalline powders and evaluated their photocatalytic activity by conducting dye photodegradation experiments under light irradiation.

\section{Experimental}

\section{Sample preparation}

$\mathrm{TiO}_{2}$ :Cex\% materials were synthesized in a reflux system for $24 \mathrm{~h}$. Titanium(IV) tetraisopropoxide (Aldrich, St. Louis, USA, 97\%) and cerium(III) nitrate (Aldrich, St. Louis, USA, 99\%) ethanolic solution were employed as precursors. Ethylene glycol and acetylacetone (Aldrich, St. Louis, USA, 99.5\%) were used as solvent and stabilizer, respectively. A stock titanium(IV) isopropoxide solution (TIP, $0.2 \mathrm{~mol} \mathrm{~L}^{-1}$ ) was prepared in ethylene glycol. For each synthesis, $25 \mathrm{~mL}$ of TIP was added to a two-neck roundbottom flask, which was kept under reflux and vigorous stirring. Then, the desired quantity of the cerium(III) nitrate ethanolic solution $\left(0.1 \mathrm{~mol} \mathrm{~L}^{-1}\right)$ was added to obtain the $\mathrm{TiO}_{2}$ :Cex $\%$ materials, with $\mathrm{x}$ varying from 0 to $50 \mathrm{~mol} \%$. After homogenization, $400 \mu \mathrm{L}$ of acetylacetone was added in $40 \mu \mathrm{L}$ portions every $10 \mathrm{~min}$. After $24 \mathrm{~h}$, the synthesized solids were filtered, washed several times with ethanol, and submitted to heating at $100{ }^{\circ} \mathrm{C}$ overnight. The sample prepared with no cerium $(0 \%)$ was labeled $\mathrm{TiO}_{2}+$ acac, and $\mathrm{TiO}_{2}$ prepared without acetylacetone was designated Pure $\mathrm{TiO}_{2}$. The as-prepared materials contained considerable quantities of organic species on their surfaces, as verified by infrared spectroscopy and thermal gravimetric analysis (Figures S1 and S2, Supplementary Information (SI) section). To eliminate these undesirable species, all the materials were calcined at $400{ }^{\circ} \mathrm{C}$ for $4 \mathrm{~h}$.

\section{Characterization}

The as-prepared samples were evaluated by Fouriertransform infrared (FTIR) spectroscopy conducted on a Shimadzu IR Prestige-21 spectrophotometer $\left(2 \mathrm{~cm}^{-1}\right.$ resolution); $\mathrm{KBr}$ pellets were used. Thermal behavior was assessed by thermogravimetry (TGA) and differential thermal analysis (DTA) on a TA Instruments SDT-Q600 Simultaneous TGA/DTA analyzer under air flow at a heating rate of $20^{\circ} \mathrm{C} \mathrm{min}^{-1}$.

Powder X-ray diffraction (PXRD) patterns of the calcined samples were registered at room temperature 
on a Bruker D8 Advanced diffractometer operating with monochromatic $\mathrm{Cu} \mathrm{K} \alpha$ radiation. Data were analyzed by Rietveld refinement with MAUD ${ }^{\circledR}$ software. ${ }^{27}$ Raman spectra were recorded at room temperature from powder samples; a Witec Alpha $300 \mathrm{R}$ spectrophotometer operating with $\mathrm{Nd}$ :YAG laser $(\lambda=532 \mathrm{~nm})$ at $7 \mathrm{~mW} \mathrm{~cm} \mathrm{~cm}^{-2}$ was employed. Sample quantities were kept constant in all measurements. Stokes-shifted Raman spectra were collected in the static mode from ca. 100 to $1000 \mathrm{~cm}^{-1}$.

Scanning electron microscopy (SEM) was performed on a Zeiss EVO50 microscope. Cerium loading in the final nanoparticles was confirmed by energy dispersive X-ray spectroscopy (EDX) on the SEM equipment coupled with EDS analysis by means of an IXRF System 500 Digital Processing accessory. Because EDS provides qualitative analyses, elementary analysis data were confirmed by total reflection X-ray fluorescence (TXRF) analysis on a Bruker S2 PICOFOX device. Many efforts were made to quantify the oxides by titration, but the usual acidic and basic conditions that are necessary to dissolve the oxides were not applicable due to their resistance to $\mathrm{pH}$ variation. Chemical states and surface composition of the samples were evaluated by X-ray photoelectron spectroscopy (XPS) on a Thermo Scientific Escalab 250Xi spectrometer operating with monochromatic AlK $\alpha$ X-rays. The flood gun was used to neutralize charge build-up on the sample surface.

Specific surface areas and pore volumes of the samples were measured by the Brunauer, Emmett and Teller (BET) method by considering $\mathrm{N}_{2}$ adsorption isotherm data. The experiments were accomplished on a Micromeritics ASAP 2020 analyzer. The samples were degassed at $200{ }^{\circ} \mathrm{C}$ for $10 \mathrm{~h}$ under vacuum to remove surface contamination and adsorbed species.

UV-Vis diffuse reflectance spectra (DRS) were recorded on an Ocean Optics HR2000+ spectrometer equipped with a UV-Vis-NIR DH-2000-BAL light source (deuterium/ halogen lamps) and reflection/backscattering probe R400-7-UV-Vis optical fiber. DRS curves were also used to determine the optical bandgap energy of all the samples. The Tauc $\mathrm{Plot}^{28}$ is commonly employed to determine the optical bandgap energy. ${ }^{29}$

\section{Photocatalysis}

The photocatalytic activity of the synthesized oxides was evaluated by methyl orange dye (MO, Merck) photodegradation under UV and visible lights, respectively simulated by a $\mathrm{Hg}$ vapor lamp $(250 \mathrm{~W})$ and a halogen lamp $(200 \mathrm{~W})$. For the experiments, $10 \mathrm{mg}$ of oxide photocatalyst were dispersed in $3.0 \times 10^{-5} \mathrm{~mol} \mathrm{~L}^{-1} \mathrm{MO}$ solution $(50 \mathrm{~mL})$. The dye solution $\mathrm{pH}$ was adjusted to $2.0 .^{30}$
Before irradiation, the dispersion was kept under magnetic agitation for $30 \mathrm{~min}$ for adsorption-desorption equilibrium between the photocatalyst and the dye to be achieved.

Photocatalytic reactions were kept under light irradiation (UV or visible lamp). An external cooling jacket with recycled water was coupled to the system to maintain the dispersion temperature at ca. $25^{\circ} \mathrm{C}$. After exposure for $0,10,20,30,60,90$, and $120 \mathrm{~min}, 2 \mathrm{~mL}$ of the dispersion was collected and filtered through a membrane filter with $0.45 \mu \mathrm{m}$ pores, to remove any solid interferences. The dye solutions were analyzed by UV-Vis absorption spectroscopy on a Hewlett Packard HP 8453 spectrophotometer.

MO was measured on the basis of its characteristic strong band with maximum absorption at $505 \mathrm{~nm}$. The Lambert-Beer equation was applied to determine the dye concentration after photocatalysis and thus its degradation in the presence of cerium-titania oxides.

The percentage of decolorization (color removal) was calculated according to equation 1 (C: concentration and Co: initial concentration).

Decolorization $(\%)=\frac{(\mathrm{Co}-\mathrm{C})}{\mathrm{Co}} \times 100$

\section{Results and Discussion}

\section{Structural characterization}

Figure 1 displays the diffraction data of the calcined samples, which all crystallized in the anatase structure (tetragonal and $\mathrm{I} 4_{1 / \text { amd }}$ space group), with no evidence of other polymorphs. We indexed the $\mathrm{TiO}_{2}$ nanoparticle diffraction peaks on the basis of JCPDS cards (PDF No. 2-406). ${ }^{31} \mathrm{~A}$ small quantity of cerium loading did not change the material phase, but we detected the $\mathrm{CeO}_{2}$ phase upon increasing cerium concentration. At $5 \mathrm{~mol} \%$ cerium, the presence of the ceria phase was confirmed through observation of broad and low-intensity peaks attributed to a cubic structure with Fm-3m space group according to the PDF 1-800 pattern. ${ }^{32}$ These peaks were considerably broad due to formation of very small $\mathrm{CeO}_{2}$ particles together with the $\mathrm{TiO}_{2}$ phase. Careful conduction of Rietveld refinement with MAUD ${ }^{\circledR}$ software ${ }^{27}$ for $\mathrm{TiO}_{2}: \mathrm{Ce}(10 \%)$ confirmed the excellent relation with the anatase structure and $\mathrm{CeO}_{2}$ emergence in a cubic structure (Figure S3, SI). When equivalent titanium and cerium species concentrations $\left(\mathrm{TiO}_{2}: \mathrm{Ce}(50 \%)\right)$ were reached, we did not observe any phase regarding $\mathrm{TiO}_{2}$ or $\mathrm{CeO}_{2}$, but we verified that the material lost crystallinity, as indicated by a completely amorphous phase.

$\mathrm{X}$-ray diffraction profiles correlate well with crystallite size and cell parameters, and these characteristics allowed 


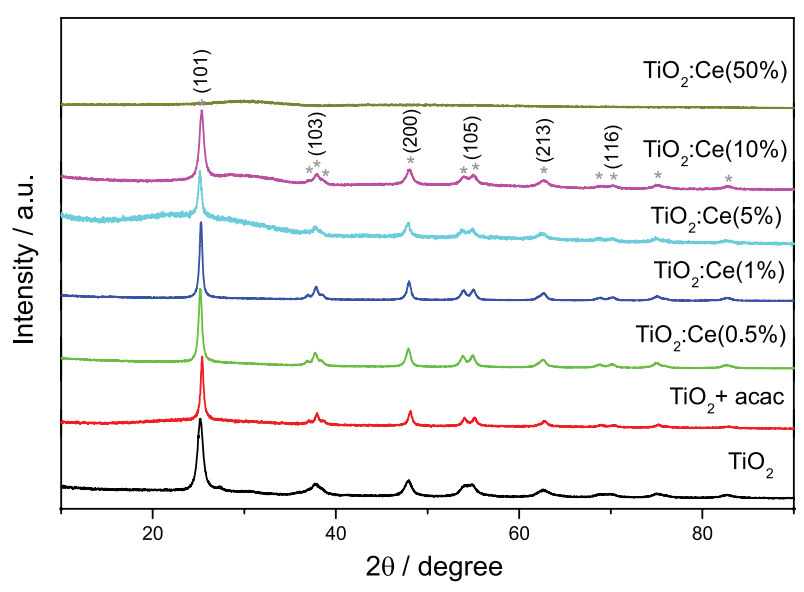

Figure 1. X-ray diffraction patterns of $\mathrm{Pure} \mathrm{TiO}_{2}, \mathrm{TiO}_{2}+$ acac, and $\mathrm{TiO}_{2}: \mathrm{Cex} \%$ systems. Anatase phase (PDF No. 2-406) ${ }^{31}$ is marked (*) inside the graph.

us to analyze how the stabilizer (acetylacetone) and the cerium amount affected the anatase structure. We calculated the crystallite size through the Scherrer formula with regard to the most intense peak (101). ${ }^{6,33}$ Figure 2 shows how the crystallite size behaved with increasing cerium concentration: the relationship between crystallite size and $\mathrm{Ce}$ mol\% was non-linear. Initially, the use of the stabilizer acetylacetone influenced the crystallite size-the unit cell expanded, and the crystallite size consequently increased. When cerium was added to the material, the crystallite size increased considerably; the largest size was reached for the sample $\mathrm{TiO}_{2}: \mathrm{Ce}(1 \%)$. Thereafter, cerium addition promoted network contraction, as indicated by a decrease in the crystallite size, which was also attributed to the formation of two different oxides $\left(\mathrm{TiO}_{2}\right.$ and $\mathrm{CeO}_{2}$ phases).

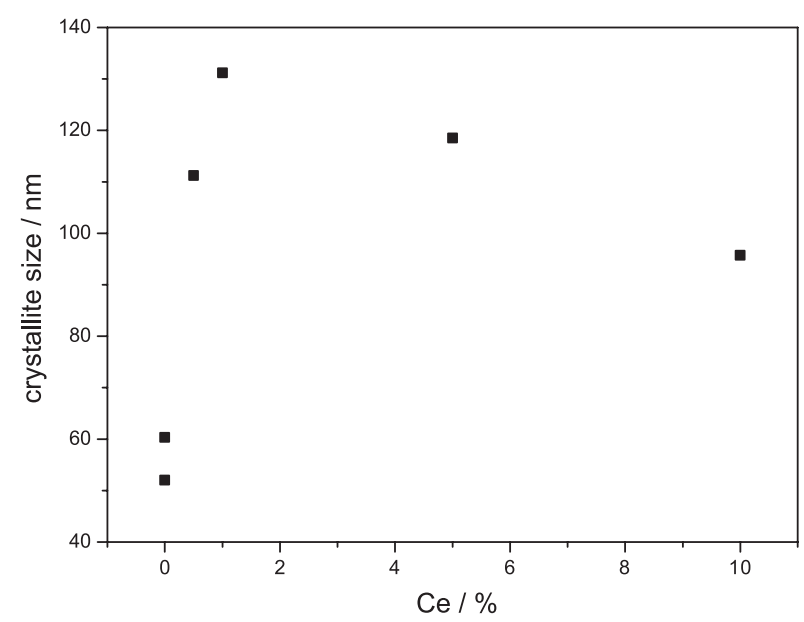

Figure 2. Crystallite size calculated by the Scherrer formula versus cerium concentration.

The Raman spectra (Figure 3) corroborated the previously discussed observations. The Raman profiles presented peaks corresponding to the vibrational modes
$E_{g}, B_{1 g}$, and $A_{1 g}$, which are typical of the $D_{2 d}$ point group and represent the anatase phase. Other $\mathrm{TiO}_{2}$ polymorphs or cubic $\mathrm{CeO}_{2}$ phase were not evident in the studied samples. The peak intensity decreased drastically, and the $\mathrm{E}_{\mathrm{g}}$ peak shifted slightly toward smaller wavenumbers, which suggested increased nanoparticle size. Any variation in the $\mathrm{E}_{\mathrm{g}}$ peak width or position signals the presence of dopants and the formation of small particles. ${ }^{15,34}$

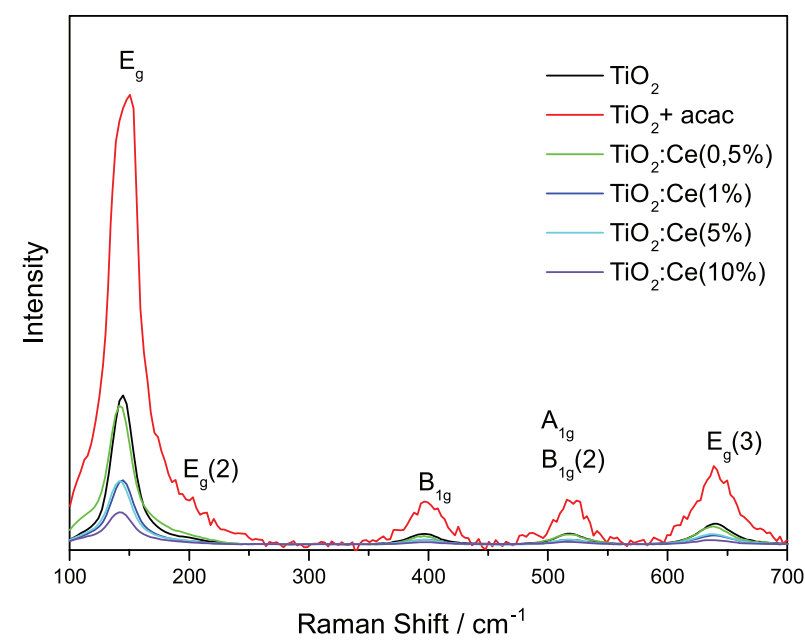

Figure 3. Raman spectra for Pure $\mathrm{TiO}_{2}, \mathrm{TiO}_{2}+$ acac, and $\mathrm{TiO}_{2}: \mathrm{Cex} \%$ systems.

We explored Pure $\mathrm{TiO}_{2}$ and cerium-modified $\mathrm{TiO}_{2}$ surface morphologies by SEM (Figure 4 and Figure S4, SI). Pure $\mathrm{TiO}_{2}$ (Figure 4a) contained rods measuring about $2 \mu \mathrm{m}$ as well as small agglomerates on the surface of these rods. The agglomerates were spherical and measured ca. $30-50 \mathrm{~nm}$ on average. Figure $4 \mathrm{~b}$ revealed that the stabilizer provided a smoother surface and increased the rod particle size.

After cerium was added to the $\mathrm{TiO}_{2}$ structure (Figures $4 \mathrm{c}-\mathrm{f}$ and Figure S4, SI), the previously described homogeneous and regular rods lost their characteristics, and the new morphology was not well defined. Porous plates consisting of spherical nanoparticles (estimated to be less than $50 \mathrm{~nm}$ ) arose. Cerium addition appeared to generate better-defined spherical particles. Cerium presence may significantly influence the surface area, as depicted in Table 2.

We confirmed the chemical compositions of the $\mathrm{TiO}_{2}: \mathrm{Cex} \%$ materials by EDS and TXRF. Both techniques gave similar results and attested that the desired amount of cerium was well incorporated into the $\mathrm{TiO}_{2}$ structure. Cerium addition to $\mathrm{TiO}_{2}$ was effective, and the chemical composition was consistent with the nominal value used during sample preparation. There were only small deviations, which tended to be higher for extreme cerium concentrations. Table 2 and Figure S5 (SI) summarize the results. 

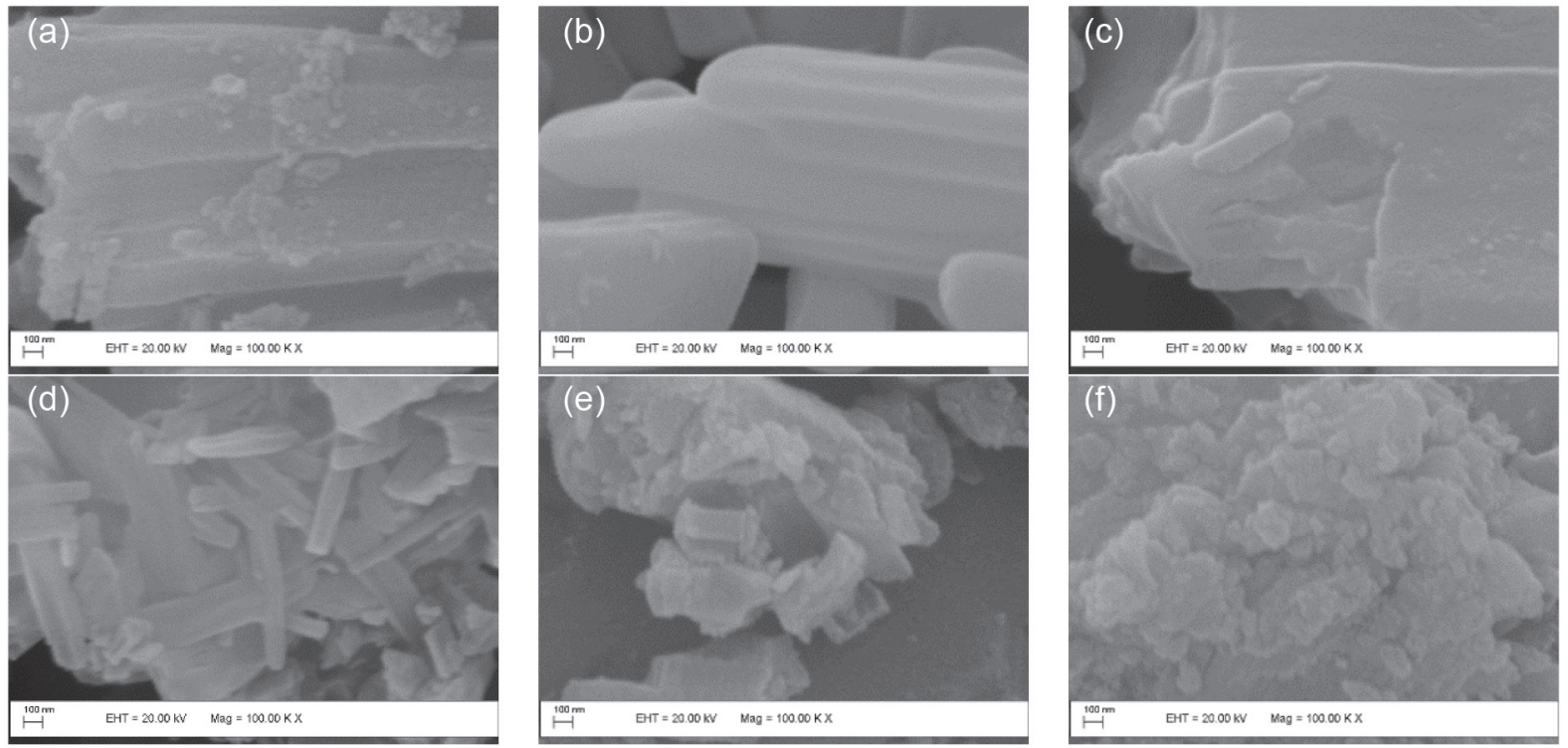

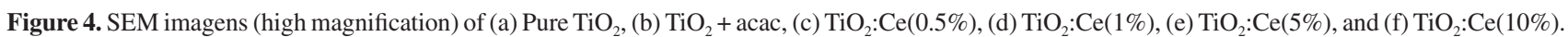

Table 2. Summarized chemical composition and textural and optical properties of $\mathrm{TiO}_{2}$-derived nanostructured materials

\begin{tabular}{|c|c|c|c|c|c|c|}
\hline Sample & $\mathrm{Ti}^{\mathrm{a}} / \%$ & $\mathrm{Ce}^{\mathrm{a}} / \%$ & Crystallite size / nm & Specific area / $\left(\mathrm{m}^{2} \mathrm{~g}^{-1}\right)$ & Pore diameter / nm & Bandgap energy / eV \\
\hline $\mathrm{TiO}_{2}$ & 100 & 0 & 52.03 & 51 & 11 & 2.93 \\
\hline $\mathrm{TiO}_{2}+\mathrm{acac}$ & 100 & 0 & 60.31 & 43 & 5 & 2.75 \\
\hline $\mathrm{TiO}_{2}: \mathrm{Ce}(0.5 \%)$ & 100 & 0 & 111.23 & 23 & 12 & 2.17 \\
\hline $\mathrm{TiO}_{2}: \mathrm{Ce}(1 \%)$ & 98.25 & 1.75 & 131.21 & 105 & 3 & 2.39 \\
\hline $\mathrm{TiO}_{2}: \mathrm{Ce}(5 \%)$ & 94.95 & 5.05 & 118.48 & 20 & 11 & 1.36 \\
\hline $\mathrm{TiO}_{2}: \mathrm{Ce}(10 \%)$ & 92.95 & 7.05 & 95.71 & 57 & 6 & 1.45 \\
\hline
\end{tabular}

${ }^{\mathrm{a}}$ Chemical composition determined by TXRF.

The chemical state of cerium species is important to investigate and to propose a mechanism for photocatalysis. An ideal $\mathrm{Ce}^{3+} / \mathrm{Ce}^{4+}$ ratio is crucial for the performance of the material studied here. We investigated the cerium chemical state and elemental composition on the material surface by XPS. The XPS survey spectrum (Figure 5 and Figure S6, SI) showed that the $\mathrm{TiO}_{2}$ :Cex\% surface was composed of Ti, O, $\mathrm{Ce}$, and $\mathrm{C}$. The carbon peak was ascribed to residual carbon from organic species employed during the synthesis and to adventitious hydrocarbons from the laboratory environment or even from the process of experimental data acquisition. The Ti $2 p_{3 / 2}$ and Ti $2 p_{1 / 2}$ binding energies were around 458.6 and $464.3 \mathrm{eV}$, respectively, for all the samples (Figure 5b), so titanium was present as $\mathrm{Ti}^{4+} .35$

We fit the characteristic $\mathrm{Ce} 3 \mathrm{~d}_{3 / 2}$ and $\mathrm{Ce} 3 \mathrm{~d}_{5 / 2}$ peaks and the $\mathrm{Ce}^{4+} / \mathrm{Ce}^{3+}$ ratio according to references. ${ }^{36}$ Figure $5 \mathrm{~d}$ shows the characteristic Ce $3 \mathrm{~d}$ spectrum, which was associated with the $\mathrm{Ce}^{3+}$ and $\mathrm{Ce}^{4+}$ chemical states for $\mathrm{TiO}_{2}: \mathrm{Ce}(5 \%)$. The Ce $3 \mathrm{~d}$ spectrum of a pure $\mathrm{Ce}^{4+}$ sample has six visible components, whereas the $\mathrm{Ce} 3 \mathrm{~d}$ spectrum of a pure $\mathrm{Ce}^{3+}$ sample has four components. These components overlapped except for the $\mathrm{Ce}^{4+}$ satellite peak located at $916 \mathrm{eV}$.

Shyu et al. ${ }^{36}$ demonstrated that the $\mathrm{Ce}^{4+}$ ratio can be estimated by dividing the $916-\mathrm{eV} \mathrm{Ce}^{4+}$ satellite peak integral area by the total $\mathrm{Ce} 3 \mathrm{~d}$ integral area according to equation 2 :

$\mathrm{Ce}(\mathrm{IV})=\frac{\text { Area }_{\mathrm{Ce}(\mathrm{IV}) \mathrm{sat}}}{\operatorname{Area}_{\mathrm{Ce} 3 \mathrm{~d}}} \frac{100}{14}$

Figure S6 (SI) presents the survey spectra for all the samples. Figure 6 compiles cerium percentages on the surface, titanium and cerium ratios, and $\mathrm{Ce}^{3+} / \mathrm{Ce}^{4+}$ ratios. Figure 6a confirmed that cerium loading was efficient, and this figure corroborated the previous EDS and XRF data. Besides, cerium addition induced the presence of $\mathrm{Ce}^{4+}$ on the material surface (Figure 6b), but appreciable $\mathrm{Ce}^{3+}$ quantities remained in all the materials, which supported lower bandgap energy.

BET adsorption of pure nitrogen revealed a porous structure, textural properties, and surface areas (Table 2). All the analyzed materials were porous and exhibited 

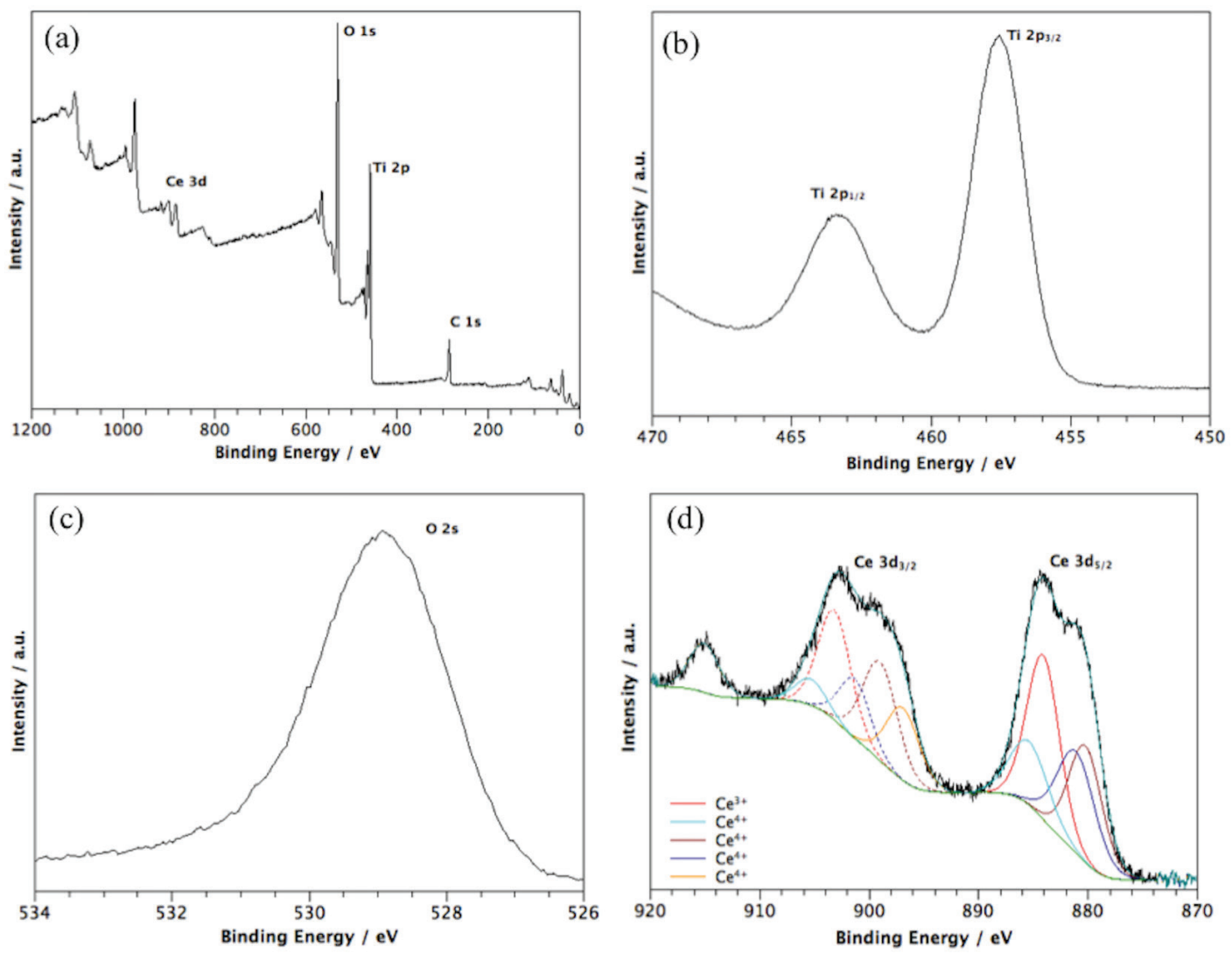

Figure 5. XPS spectrum of $\mathrm{TiO}_{2}$ : $\mathrm{Ce}(5 \%$ ): (a) survey, (b) Ti 2p, (c) O 1s, and (d) Ce 3d (SI contains the spectra of all the samples).
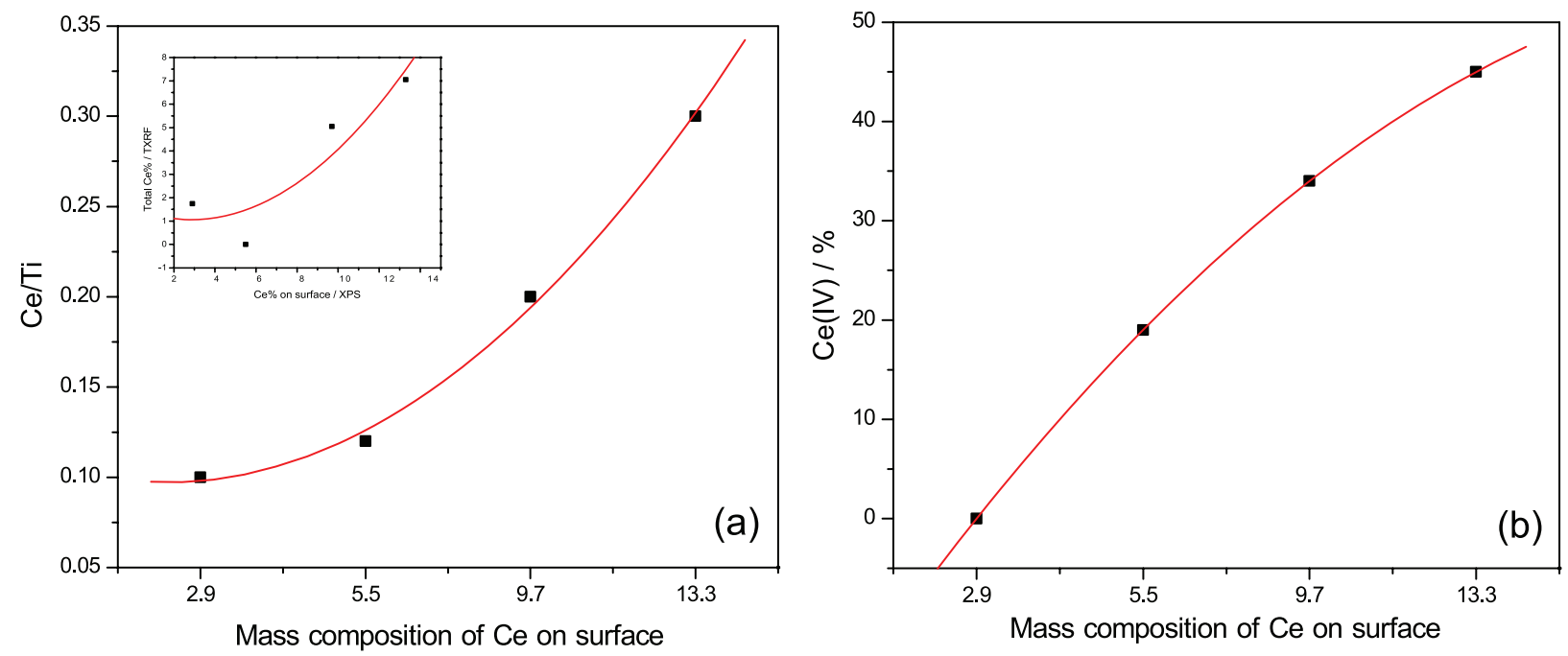

Figure 6. Increase in (a) cerium quantities (insert curve: XPS $\times$ XRF cerium composition), and (b) $\mathrm{Ce}^{4+}$ species with cerium addition from 0.5 to $10 \%$.

a typical type IV isotherm with hysteresis loops (H2 and $\mathrm{H} 3$ types). Initially, acetylacetone addition during the synthesis drastically decreased the specific surface area, which was also observed by SEM. However, the specific surface area gradually increased with cerium content and reached values comparable to the $\mathrm{Pure}_{\mathrm{TiO}}$ specific surface area, which could enhance photocatalytic performance.
We measured the optical properties of $\mathrm{Pure}_{\mathrm{TiO}}$ and the $\mathrm{TiO}_{2}$ :Cex\% materials by diffuse reflectance spectroscopy (DRS) at room temperature. Figure 7 illustrates the UV-Vis absorption of the samples. Cerium addition increased visible radiation absorption and consequently decreased the bandgap energy of the materials. The results confirmed that the materials absorbed part of the solar radiation. Thus, solar energy can be applied in photocatalytic reactions 
performed in the presence of $\mathrm{TiO}_{2}: \mathrm{Cex} \%$. Bandgap energy values are very important to describe semiconductor properties. The bandgap energy data indicate the energy difference between the valence band (VB) and conduction band (CB). Using the relation of Tauc et al. ${ }^{28}$ (Figure S7, $\mathrm{SI}$ ), we determined the bandgap energy values and related them to cerium addition (Figure 8). The bandgap energy decreased with increasing cerium concentration (Table 2). Pure $\mathrm{TiO}_{2}$ had bandgap energy ca. $2.93 \mathrm{eV}$, which resembled the found in the literature for $\mathrm{TiO}_{2}$ in the anatase phase. ${ }^{21,37}$ Pure $\mathrm{TiO}_{2}$ synthesized with acetylacetone displayed considerably lower bandgap energy, which indicated that the stabilizer exerted a unique effect. Nevertheless, acetylacetone introduction had an undesirable influence on surface area. On the other hand, cerium addition to $\mathrm{TiO}_{2}$ provided low bandgap energy covering the entire solar radiation spectrum; the minimum was near $1.25 \mathrm{eV}$. The XPS data showed that cerium was present in all the samples, which was beneficial because it shifted light absorption toward the visible region. Furthermore, cerium increased the specific surface area.

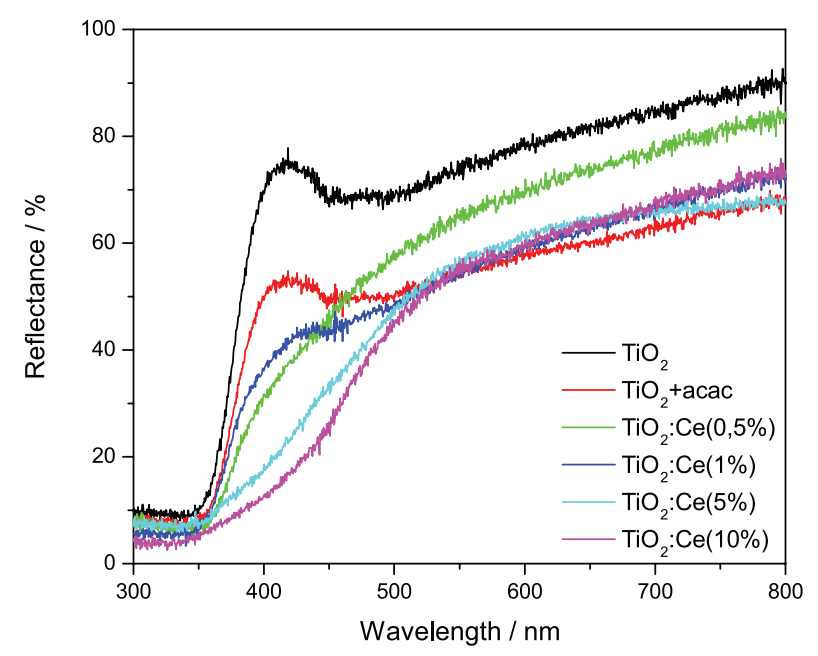

Figure 7. Reflectance diffuse spectra for $\mathrm{Pure} \mathrm{TiO}_{2}, \mathrm{TiO}_{2}+$ acac, and $\mathrm{TiO}_{2}: \mathrm{Cex} \%$ systems.

\section{Photocatalytic activity}

We evaluated the photocatalytic activities of $\mathrm{TiO}_{2}$ and $\mathrm{TiO}_{2}$ :Cex\% powders by conducting methyl orange dye (MO) degradation experiments under irradiation with UV and visible light. The experiments lasted $120 \mathrm{~min}$, which is adequate for practical photocatalytic process applications in water treatment. ${ }^{38}$ We also carried out MO photodegradation experiments without the photocatalyst (photolysis) in the same conditions and achieved ca. $0.2 \%$ degradation. Thus, the occurrence of photolysis can be dismissed. The initial MO concentration and $\mathrm{pH}$ were

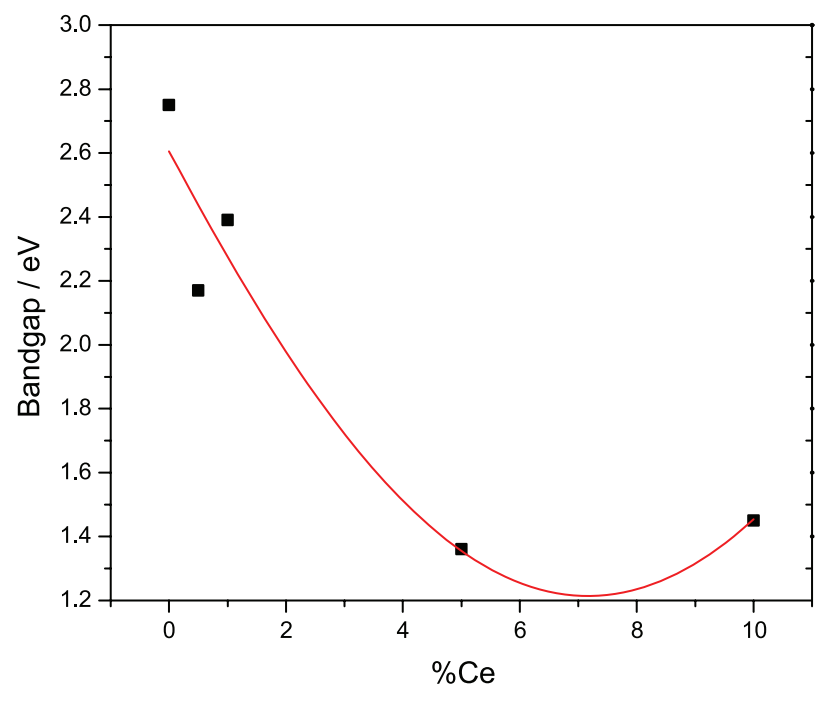

Figure 8. Effect of cerium content on bandgap energy.

$10 \mathrm{ppm}$ and ca. 2.0, respectively, so we analyzed MO in its protonated form. We monitored the decolorization process and overlay the UV-Vis spectra obtained at different times (examples in Supplementary Information section, Figure S8). We determined MO on the basis of the most intense band at $\lambda$ ca. $505 \mathrm{~nm}$. For both irradiation lamps, the recorded spectra presented a less intense band in the UV region, which could indicate MO mineralization. ${ }^{38}$

Figure 9 described the photocatalytic performances of the nanostructured $\mathrm{TiO}_{2}: \mathrm{Cex} \%$ materials in $\mathrm{MO}$ degradation as plots of $\mathrm{C} / \mathrm{C}_{0}$ versus $\mathrm{t}(\mathrm{min})$. A balance in the oxide properties (cerium amount, cerium chemical state, bandgap energy, specific surface area, and pore size) seemed to influence the final photocatalysis. In this study, the best photocatalyst for MO degradation was the material containing higher cerium amount $\left(\mathrm{TiO}_{2}: \mathrm{Ce}(10 \%)\right)$, which presented elevated specific surface area, lower bandgap energy, and higher $\mathrm{Ce}^{4+}$ quantities. The increase in the constant degradation rates was attributed to efficient charge separation in the photoexcited semiconductors and to the degradation mechanism based on radical species formation, which are both well described in the literature..$^{26,39}$

The XPS results showed that $\mathrm{TiO}_{2}: \mathrm{Ce}(10 \%)$ had about $45 \%$ of $\mathrm{Ce}^{4+}$ and $55 \%$ of $\mathrm{Ce}^{3+}$ on its surface (Table $\mathrm{S} 1, \mathrm{SI}$ ). The mechanism of charge separation on photocatalysts is usually based on electron transfer from the $\mathrm{TiO}_{2}$ conductive band to the $\mathrm{Ce}^{4+}$ electronic states, followed by $\mathrm{Ce}^{4+}$ reduction to $\mathrm{Ce}^{3+}, 25,26$ as illustrated in Figure 10 . This mechanism prolongs the photogenerated electronhole $\left(\mathrm{e}^{-} / \mathrm{h}^{+}\right)$lifetime, thereby enhancing the photocatalytic activity. Therefore, $\mathrm{Ce}^{4+} / \mathrm{Ce}^{3+}$ acts as an electron trap and provides superoxide radicals, thus contributing both to organic pollutant degradation and to lower photo-induced $\mathrm{e}^{-} / \mathrm{h}^{+}$pair recombination rate. ${ }^{40,41}$ It is noteworthy that we 

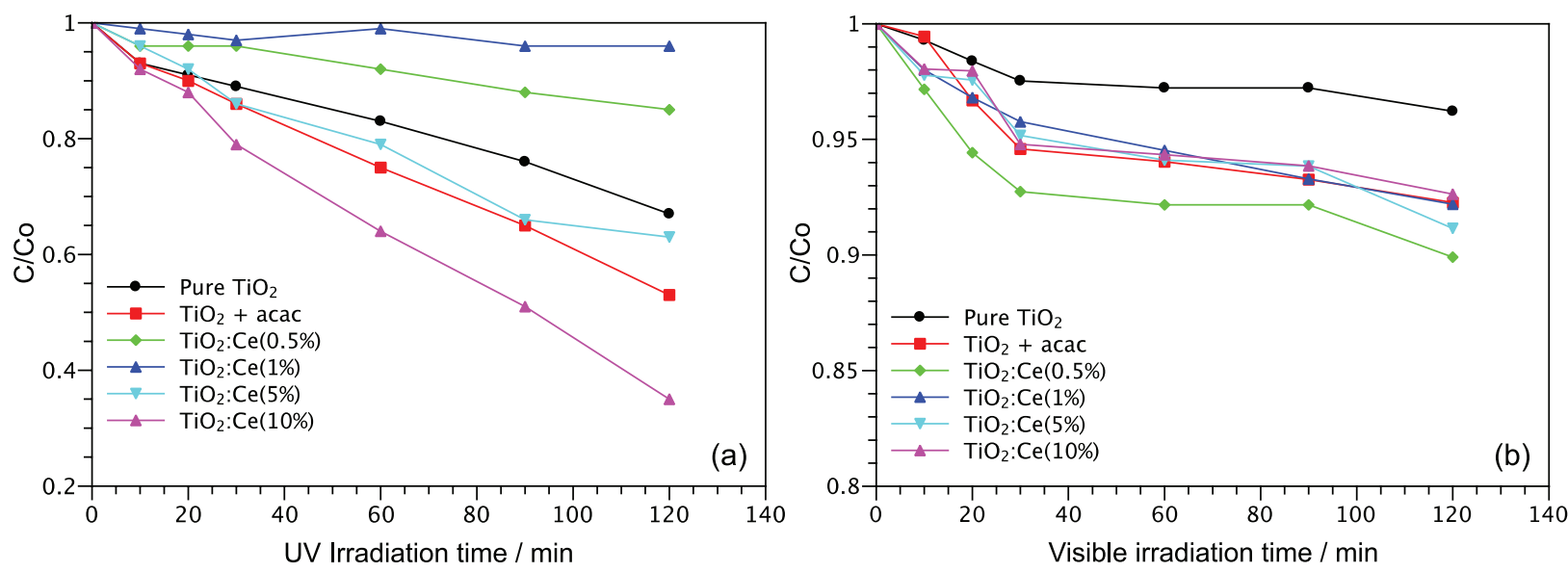

Figure 9. Photocatalytic activity of cerium-doped $\mathrm{TiO}_{2}$ materials for the degradation of (a) protonated methyl orange $(\mathrm{pH}=2.0)$ under $(\mathrm{a}) \mathrm{UV}$ and (b) visible radiation.

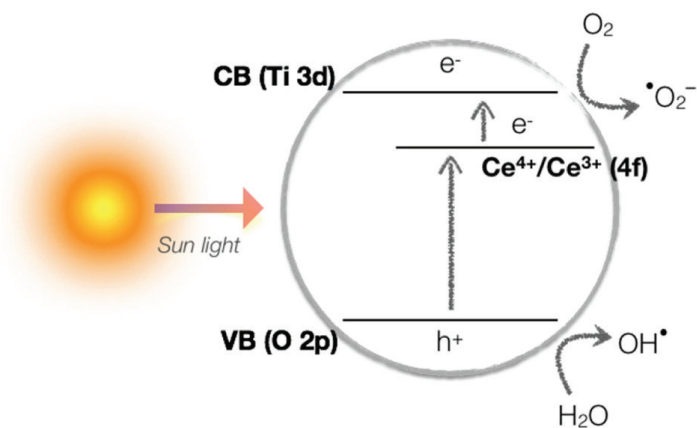

Figure 10. Schematic representation of photocatalytic activity process for cerium-doped $\mathrm{TiO}_{2}$ materials.

accomplished photocalytic MO degradation in acidic medium, which could also have influenced the oxide surface. Figure 11 summarizes the total decolorization percentage after $120 \mathrm{~min}$. A pronounced difference in the behavior of different photocatalysts under UV and visible light is evident. Nevertheless, by considering the

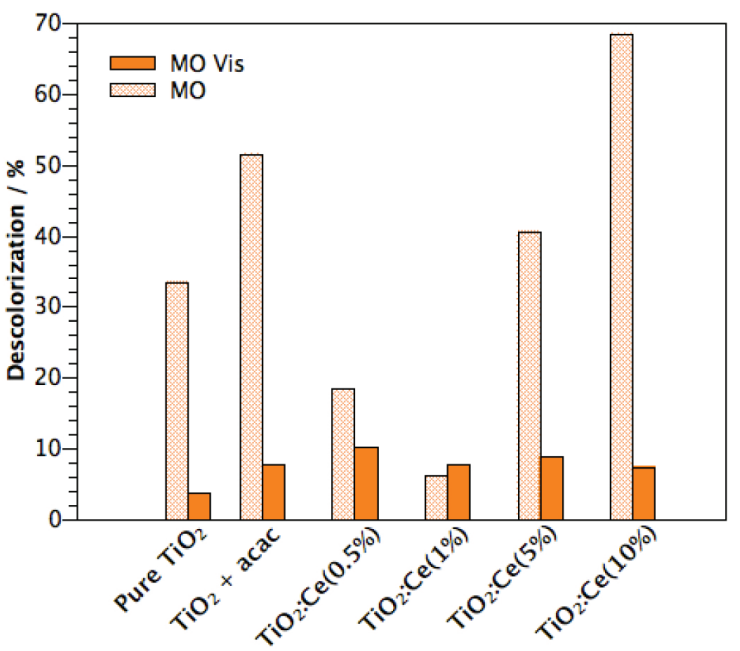

Figure 11. Percentage of MO dye decolorization after exposure to light for $120 \mathrm{~min}$ total decolorization under UV-Vis radiation, we are able to confirm that the cerium content was essential for better photodegradation and expansion of the solar spectrum absorption.

\section{Conclusions}

We synthesized nanostructured $\mathrm{TiO}_{2}$ and cerium-doped $\mathrm{TiO}_{2}$ materials with ordered structure by a modified sol-gel method by employing acetylacetone, as stabilizer, and titanium isopropoxide and cerium nitrate, as precursors. We examined how the stabilizer and the loading of different cerium amounts affected the anatase $\mathrm{TiO}_{2}$ optical and structural properties. Furthermore, we evaluated the photocatalytic efficiency of the prepared materials in methyl orange dye photodegradation experiments.

The set of data indicates that the addition of small amounts of cerium ions to the $\mathrm{TiO}_{2}$ lattice increased the photosensitivity to visible light. The bandgap energy reached $1.45 \mathrm{eV}$, and the presence of $\mathrm{Ce}^{3+}$ ions was fundamental for ideal bandgap energies to be achieved. High specific surface area and/or pore size associated with ideal bandgap energy seemed to be essential for better photocatalyst performance. In addition, balanced $\mathrm{Ce}^{4+} / \mathrm{Ce}^{3+}$ quantities allowed organic pollutant degradation through generation of reactive oxygen species and efficient $\mathrm{e}^{-} / \mathrm{h}^{+}$pair separation.

We conducted photocatalytic tests for methyl orange dye degradation in the presence of the solids under UV radiation in mild conditions. Low photocatalyst concentration $(10 \mathrm{mg})$ and fast exposure to light $(120 \mathrm{~min})$ afforded good dye degradation. Cerium content was crucial for better photodegradation. $\mathrm{The}^{\mathrm{TiO}_{2}}$ : $\mathrm{Cex} \%$ photocatalysts showed superior photocatalytic activity as compared to Pure $\mathrm{TiO}_{2}$, and $\mathrm{TiO}_{2}: \mathrm{Cex} \%$ were able to use solar radiation for a photodegradation process. 


\section{Supplementary Information}

Supplementary information (additional characterizations) is available free of charge at http://jbcs.sbq.org.br as PDF file.

\section{Acknowledgments}

We thank the Brazilian funding agencies $(\mathrm{CNPq}$, FAPERJ, and CAPES) for the support provided for this research. Prof R. B. Guimarães (Fluminense Federal University), Prof K. Araki, and Dr E. Castaldelli (LQSN University of São Paulo), and Prof O. A. Serra (Rare Earth Laboratory - University of São Paulo) are acknowledged for analyses and helpful discussions.

\section{References}

1. Josephine, G. S.; Sivasamy, A.; Appl. Catal., B 2014, 150, 288.

2. Silva, A. M. T.; Silva, C. G.; Dražić, G.; Faria, J. L.; Catal. Today 2009, 144, 13.

3. Rao, M. P.; Nandhini, V. P.; Wu, J. J.; Syed, A.; Ameen, F.; Anandan, S.; J. Solid State Chem. 2018, 258, 647.

4. Khelifi, E.; Ayed, L.; Bouallagui, H.; Touhami, Y.; Hamdi, M.; J. Hazard. Mater. 2009, 163, 1056.

5. Meehan, C.; Banat, I. M.; McMullan, G.; Nigam, P.; Smyth, F.; Marchant, R.; Environ. Int. 2000, 26, 75.

6. Prasanna kumar, J. B.; Ramgopal, G.; Vidya, Y. S.; Anantharaju, K. S.; Daruka Prasad, B.; Sharma, S. C.; Prashantha, S. C.; Premkumar, H. B.; Nagabhushana, H.; Spectrochim. Acta, Part A 2015, 141, 149.

7. Nilsson, I.; Möller, A.; Mattiasson, B.; Rubindamayugi, M. S. T.; Welander, U.; Enzyme Microb. Technol. 2006, 38, 94.

8. Chen, Y.; Wu, Q.; Zhou, C.; Jin, Q.; Powder Technol. 2017, 322, 296.

9. Byrne, C.; Subramanian, G.; Pillai, S. C.; J. Environ. Chem. Eng. 2017, 6, 3531.

10. Li, J.; Zhang, J. Z.; Coord. Chem. Rev. 2009, 253, 3015.

11. Kanakaraju, D.; Glass, B. D.; Oelgemöller, M.; J. Environ. Manage. 2018, 219, 189.

12. Brienza, M.; Mahdi Ahmed, M.; Escande, A.; Plantard, G.; Scrano, L.; Chiron, S.; Bufo, S. A.; Goetz, V.; Chemosphere 2016, 148, 473.

13. Sharma, A.; Ahmad, J.; Flora, S. J. S.; Environ. Res. 2018, 167, 223.

14. Devi, L. G.; Kavitha, R.; Appl. Catal., B 2013, 140, 559.

15. Fonseca de Lima, J.; Harunsani, M. H.; Martin, D. J.; Kong, D.; Dunne, P. W.; Gianolio, D.; Kashtiban, R. J.; Sloan, J.; Serra, O. A.; Tang, J.; Walton, R. I.; J. Mater. Chem. A 2015, 3, 9890.

16. Yan, N.; Zhu, Z.; Zhang, J.; Zhao, Z.; Liu, Q.; Mater. Res. Bull. 2012, 47, 1869.

17. Štengl, V.; Bakardjieva, S.; Murafa, N.; Mater. Chem. Phys. 2009, 114, 217.
18. Matějová, L.; Kočí, K.; Reli, M.; Čapek, L.; Hospodková, A.; Peikertová, P.; Matěj, Z.; Obalová, L.; Wach, A.; Kuśtrowski, P.; Kotarba, A.; Appl. Catal., B 2014, 152, 172.

19. Yasmina, M.; Mourad, K.; Mohammed, S. H.; Khaoula, C.; Energy Procedia 2014, 50, 559.

20. Kandiel, T. A.; Dillert, R.; Feldhoff, A.; Bahnemann, D. W.; Chem. Mater. 2010, 22, 4909.

21. Muñoz-Batista, M. J.; de los Milagros Ballari, M.; Kubacka, A.; Cassano, A. E.; Alfano, O. M.; Fernández-García, M.; Chem. Eng. J. 2014, 255, 297.

22. Zholobak, N. M.; Ivanov, V. K.; Shcherbakov, A. B.; Shaporev, A. S.; Polezhaeva, O. S.; Baranchikov, A. Y.; Spivak, N. Y.; Tretyakov, Y. D.; J. Photochem. Photobiol., B 2011, 102, 32.

23. Zhang, D.; Du, X.; Shi, L.; Gao, R.; Dalton Trans. 2012, 41, 14455.

24. Walton, R. I.; Prog. Cryst. Growth Charact. Mater. 2011, 57, 93.

25. Chen, Y.; Liu, K.; J. Hazard. Mater. 2017, 324, 139.

26. Chen, Y.; Wu, Q.; Zhou, C.; Jin, Q.; Adv. Powder Technol. 2018, $29,106$.

27. Lutterotti, L.; Matthies, S.; Wenk, H.-R.; IUCr: Newsletter of the CPD 1999, 21, 14.

28. Tauc, J.; Grigorovici, R.; Vancu, A.; Phys. Status Solidi 1966, 15,627 .

29. de Lima, J. F.; Martins, R. F.; Serra, O. A.; Opt. Mater. 2012 , $35,56$.

30. Sejie, F. P.; Nadiye-tabbiruka, M. S.; Phys. Chem. 2016, 6, 39.

31. Weiseh, H. B.; Milligan, W. O.; J. Phys. Chem. 1932, 36, 3010.

32. Hanawalt, J. D.; Rinn, H. W.; Frevel, L. K.; Ind. Eng. Chem., Anal. Ed. 1938, 10, 457.

33. Lima, J. F.; Martins, R. F.; Neri, C. R.; Serra, O. A.; Appl. Surf. Sci. 2009, 255, 9006.

34. Capdevila-Cortada, M.; Vilé, G.; Teschner, D.; Pérez-Ramírez, J.; López, N.; Appl. Catal., B 2016, 197, 299.

35. Biesinger, M. C.; Lau, L. W. M.; Gerson, A. R.; Smart, R. S. C.; Appl. Surf. Sci. 2010, 257, 887.

36. Shyu, J. Z.; Otto, K.; Watkins, W. L. H.; Graham, G. W.; Belitz, R. K.; Gandhi, H. S.; J. Catal. 1988, 114, 23.

37. Pei, L. Z.; Liu, H. D.; Lin, N.; Yu, H. Y.; Mater. Res. Bull. 2015 , $61,40$.

38. Lutic, D.; Petrovschi, D.; Ignat, M.; Creţescu, I.; Bulai, G.; Catal. Today 2018, 306, 300.

39. Touati, A.; Hammedi, T.; Najjar, W.; Ksibi, Z.; Sayadi, S.; J. Ind. Eng. Chem. 2016, 35, 36.

40. Xie, J.; Jiang, D.; Chen, M.; Li, D.; Zhu, J.; Lü, X.; Yan, C.; Colloids Surf., A 2010, 372, 107.

41. Tomova, D.; Iliev, V.; Eliyas, A.; Rakovsky, S.; Sep. Purif. Technol. 2015, 156, 715.

Submitted: January 21, 2019

Published online: June 28, 2019 